\title{
Patterns and Predictors of Fast Food Consumption After Acute Myocardial Infarction
}

\author{
Adam C. Salisbury, MD, MSc ${ }^{a, b}$, Paul S. Chan, MD, MSc ${ }^{a, b}$, Kensey L. Gosch, MS ${ }^{a}$, Donna \\ M. Buchanan, PhD ${ }^{a, b}$, and John A. Spertus, MD, MPH ${ }^{a, b}$ \\ a Saint Luke s Mid-America Heart and Vascular Institute, Kansas City, MO \\ b University of Missouri-Kansas City, Kansas City, MO
}

\section{Abstract}

Although fast food is affordable and convenient, it is also high in calories, saturated fat and sodium. The frequency of fast food intake at the time of, and after, acute myocardial infarction (AMI) is modifiable. However, patterns of fast food intake and characteristics associated with its consumption among AMI patients are unknown. We studied fast food consumption at the time of AMI and 6 months later in 2481 patients from the prospective, 24-center TRIUMPH study of AMI patients. Fast food intake was categorized as frequent ( $\geq$ weekly) vs. infrequent (< weekly). Multivariable log-binomial regression was used to identify patient characteristics associated with frequent fast food intake 6 months after AMI. At baseline, 884 patients (36\%) reported frequent fast food intake, which decreased to 503 (20\%) 6 months after discharge (p-value <0.001). Male sex, white race, lack of college education, current employment and dyslipidemia were independently associated with frequent fast food intake 6 months after AMI. In contrast, older patients and those who had coronary bypass surgery were less likely to eat fast food frequently. Documentation of discharge dietary counseling was not associated with 6-month fast food intake. In conclusion, fast food consumption by AMI patients declined 6 months after the index hospitalization, but certain populations, including younger patients, men, those currently working, and less educated patients were more likely to consume fast food, at least weekly, during followup. Novel interventions that go beyond traditional dietary counseling may be needed to address continued fast food consumption after AMI in these patients.

\section{Keywords \\ myocardial infarction; diet; fast food}

Corresponding author: Adam C. Salisbury, MD, MAHI, $5^{\text {th }}$ Floor, 4401 Wornall Road, Kansas City, MO 64111, Phone: 816-932-5708 Fax: 816-932-5613, salisburya@umkc.edu.

Data Access and Responsibility:

Drs. Salisbury and Spertus had full access to all of the data in the study and take responsibility for the integrity of the data and the accuracy of the data analysis.

Conflict of Interest and Disclosures:

Adam C. Salisbury, MD, MSc: none

Paul S. Chan, MD, MSc: none

Kensey L. Gosch, MS: none

Donna M. Buchanan, PhD: none

John A. Spertus, MD, MPH: none

Publisher's Disclaimer: This is a PDF file of an unedited manuscript that has been accepted for publication. As a service to our customers we are providing this early version of the manuscript. The manuscript will undergo copyediting, typesetting, and review of the resulting proof before it is published in its final citable form. Please note that during the production process errors may be discovered which could affect the content, and all legal disclaimers that apply to the journal pertain. 
We sought to describe patterns of fast food consumption at the time of acute myocardial infarction (AMI) and in follow-up among AMI patients in the 24-center Translational Research Investigating Underlying disparities in acute Myocardial infarction Patients Health Status (TRIUMPH) study. We ascertained the prevalence of frequent fast food intake at the time of admission with AMI and 6 month later. To identify populations of patients who frequently consume fast food after discharge, we then the examined patient characteristics associated with the post-discharge consumption of fast food more often than once a week. Finally, given the potential importance of discharge dietary counseling, which has been proposed as a potential quality measure in AMI care ${ }^{1}$ and adopted as an indicator of quality in heart failure care, 2 we examined the association of dietary counseling during the index hospitalization with frequent fast food consumption 6 months later.

\section{METHODS}

We studied patients enrolled between April 11, 2005 and December 31, 2008 in the TRIUMPH study, a prospective observational registry of patients with AMI from 24 centers across the United Status. Patients were eligible for inclusion if they were 18 years of age or older with elevated cardiac biomarkers (troponin or creatine kinase-MB within 24 hours of admission), supporting evidence of AMI (electrocardiographic changes or prolonged ischemic signs/symptoms) and presented to the enrolling institution or were transferred to that facility within 24 hours of presentation. Patients were excluded if they had elevated biomarkers after an elective revascularization, refused participation, could not provide consent or were currently incarcerated. Trained data collectors performed detailed baseline chart abstractions to document patients medical history, processes of inpatient care, laboratory results and treatments. Each patient also underwent a standardized interview by research staff to document further demographic, socioeconomic and clinical data. Patients were then contacted for 6-month follow-up interviews. All patients provided written informed consent and the study protocol was approved by the institutional review board at each participating institution.

Among 4340 patients who provided consent and were enrolled into TRIUMPH, we excluded 24 patients who died before discharge and 55 patients who did not respond to the fast food question on the baseline interview. We also excluded 1780 patients missing 6-month fast food consumption data (1093 were lost to follow-up before 6-month follow-up interviews, 180 refused follow-up interview, 157 died, 93 were too ill to complete the interview and 257 did not respond to the 6-month fast food assessment) leaving a final study cohort of 2481 patients.

To assess the frequency of fast food consumption, patients were interviewed prior to discharge and 6 months later and asked: "How often do you eat at fast food restaurants?" Five responses were possible: "Less than once a month," "1-3 times a month," "1-2 times a week," "3-4 times a week," or "5 or more times a week." The latter two categories were collapsed into a single fast food group since both represent very heavy fast food intake. We further categorized fast food intake into frequent fast food consumption (weekly or greater) and infrequent consumption (less than weekly).

Although our fast food assessment has not been previously validated, a similar single-item question assessing fast food intake was shown to be associated with poor diet quality in the Multi-Ethnic Study of Atherosclerosis cohort.3 In this study, patients who reported frequent fast food intake were more likely to have poor overall diet quality as assessed by detailed instruments, including a higher intake of fats and processed meats. We also compared the mean red blood cell omega- 3 fatty acid levels 4 by category of fast food consumption in a TRIUMPH substudy of 1487 patients who had concurrent red blood cell omega-3 level 
assessment and dietary assessment data. Omega-3 levels reflect overall diet quality over a three month time span, similar to hemoglobin A1C as a time-averaged marker of blood glucose levels. The clinical logic was that fast food is low in omega-3 fatty acids and high in omega- 6 fatty acids, and that those with greater fast food consumption should have lower omega- 3 levels. A red blood cell omega- 3 level $<4 \%$ has been shown to be associated with increased mortality and sudden cardiac death while a level of $>8 \%$ is protective. $4^{, 5} \mathrm{We}$ found that an omega-3 level <4\% was present in 102 of 537 patients (19\%) who consumed fast food $\leq$ monthly, 120 of 423 patients (28\%) eating fast food 1-3 times/month, 85 of 295 (29\%) in eating fast food 1-2 times/week and in 88 of 234 (38\%) eating fast food more $\geq 3$ times/week $(\mathrm{p}<0.001)$. Conversely, favorable omega-3 levels of $>8 \%$ were seen in $39(7 \%)$, $25(5.9 \%), 7(2.4 \%)$ and 4 patients $(1.7 \%)$, respectively $(\mathrm{p}<0.001)$. Both of these comparisons were highly statistically significant and support the validity of the primary outcome for this study.

An important goal of our study was to describe the relationship between socioeconomic status and fast food eating patterns. To accomplish this, we collected information on patients level of education, which was categorized as having or not having a college degree. Patients monthly financial status was assessed with the following question, "In general, how do your finances usually work out at the end of the month? Do you usually end up with: Some money left over, just enough to make ends meet or not enough to make ends meet?" Patient reported employment status was collected by asking "Do you currently work for pay" with responses recorded as "Yes, full time," "Yes, part time" or "No". A patient was considered currently employed for these analyses if they reported full or part time work at the time of enrollment. We assessed depressive symptoms using the Patient Health Questionnaire-9, using a threshold score of $\geq 10$ to identify depressed patients. ${ }^{6-8}$

Baseline characteristics among those with and without frequent fast food intake were compared using independent Student s t-tests for continuous variables and chi-square tests for categorical variables. Given that the outcome of frequent fast food intake was common, we used multivariable log-binomial regression to identify independent predictors at the time of AMI of frequent fast food intake at 6 month follow-up. Hierarchical analyses were conducted, with hospital site as a random effect, to account for clustering of patient characteristics within hospitals. We selected, a priori, the following variables for inclusion in the model: sociodemographics (age, gender, race [white vs. other]), education (college vs. no college degree, monthly financial difficulty, employment status), clinical factors (current smoking, obesity [body mass index $\geq 30 \mathrm{~kg} / \mathrm{m} 2$ ], diabetes mellitus, hypertension, chronic heart failure, dyslipidemia, history of prior myocardial infarction, depression), characteristics of the index AMI (ST-elevation vs. non-ST-elevation AMI, treatment with percutaneous coronary intervention $[\mathrm{PCI}]$ or coronary artery bypass grafting [CABG]) and provision of dietary counseling at discharge. Among those with 6-month follow-up data, a total of 101 patients were missing data on the body mass index variable. A smaller number of observations were missing for several other variables (race: 6 patients, education: 4 patients, smoking status: 13 patients, working status: 15 patients and financial status in 38 patients). To allow the models to run on the entire cohort with 6-month follow-up, we imputed these missing data using IVEWARE software. ${ }^{9}$

To assess for selection bias in our findings due differences between those patients with and without 6-month follow-up data, we created a non-parsimonious model for the propensity of missing 6-month follow-up data. The reciprocal of this probability was used to weight the associations among responders in the regression model. Results with and without weighting were similar, thus, only the original analyses are reported. 


\section{RESULTS}

During the index AMI hospitalization, 884 patients (36\%) reported eating fast food frequently. Very frequent fast food intake ( $\geq 3$ times weekly) was reported by 391 patients $(16 \%)$ (Figure 1). The proportion frequently consuming fast food consumption declined by 6 month follow-up ( $\geq$ weekly: 503 patients [20\%], $\geq 3$ times weekly: 139 patients [6\%]). Although only 877 patients (35\%) reported rarely eating fast food (< monthly) at the time of their AMI, $1279(52 \%)$ reported less than monthly fast food consumption at 6 months. There were several important differences in the baseline characteristics of patients reporting frequent and infrequent 6-month fast food intake (Table 1). In both patients who did and did not eat fast food frequently, the majority of patients had documented dietary counseling before discharge from the hospital.

Several patient characteristics were independently associated with frequent fast food intake 6 months after discharge (Figure 2). Older patients were less likely to report frequent fast food consumption at 6 months (per 10 year increase: RR 0.87, 95\% CI 0.81-0.95, $\mathrm{p}=0.001$ ). In contrast, men (RR 1.32, 95\% CI 1.10-1.60, $\mathrm{p}=0.004$ ) and Caucasians (RR 1.41, 95\% CI $1.13-1.77, \mathrm{p}=0.002)$ were more likely eat fast food frequently at follow-up. Similarly, patients who did not have a college degree $(1.27,95 \%$ CI 1.08-1.49, $\mathrm{p}=0.004)$, those who were currently employed (RR $1.32,95 \%$ CI $1.10-1.59, \mathrm{p}=0.003$ ) and patients with dyslipidemia (RR $1.22,95 \%$ CI 1.04-1.44, $\mathrm{p}=0.02$ ) reported heavy fast food intake more frequently. Finally, patients who underwent CABG (RR 0.69, 95\% CI 0.50-0.95, p=0.02) during the index AMI were less likely to report frequent 6 month fast food intake. Notably, documentation of dietary counseling at discharge was not associated with 6-month fast food intake (RR 1.05, 95\% CI 0.79-1.40, $\mathrm{p}=0.73$ ). The model adequately discriminated frequent fast food consumption with a c-statistic of 0.66 .

\section{DISCUSSION}

Despite guidelines that emphasize adoption of a healthy low-fat diet after AMI, ${ }^{10,11}$ to our knowledge, the patterns and predictors of fast food consumption after AMI have not been described. We noted that frequent, self-reported, fast food intake was common, reported by 1 in 3 patients at the time of AMI. Although we observed a significant reduction in fast food consumption during follow-up, frequent fast food consumption remained common, being reported by 1 in 5 patients 6 months after suffering an AMI. In particular, men, patients without a college education, those currently working and those with dyslipidemia were more likely to report frequent fast food consumption 6 months after AMI, while older patients and those undergoing coronary artery bypass surgery were less likely. Importantly, although discharge documentation indicated dietary counseling was provided to the majority of patients before leaving the hospital, we found no association between this intervention and lower fast food consumption at 6-month follow-up.

Several of the patient characteristics we found to be associated with frequent fast food consumption may be useful to identify patients who need more intense interventions to improve their dietary habits after an AMI. Our finding that younger age, male sex and lower education were associated with greater fast food intake is consistent with prior epidemiologic literature that found that these characteristics were associated with general measures of poorer diet quality. ${ }^{12-16}$ Our study extends these observations by finding robust associations between these characteristics and patient-reported fast food behavior in a large, contemporary sample of patients with AMI, after extensive adjustment for a broad array of potential confounders. Further study is needed to determine whether targeting diet interventions to these populations improves adherence to guideline recommended dietary practices. 
The relation between fast food behavior and employment status is intriguing, potentially suggesting that hectic work schedules and workplace environments predispose individuals to consume fast food products. Food eaten away from home is often higher in calories and saturated fat, ${ }^{17}$ which is consistent with our finding that working patients ate fast food more frequently. The association between dyslipidemia and fast food intake is also interesting. A host of other cardiac risk factors were not independently associated with frequent fast food intake (diabetes, hypertension, obesity and smoking), while dyslipidemia was associated with a greater likelihood of eating fast food. Further research is needed to understand this relationship, which may reflect that novel dietary education and counseling strategies are needed to reinforce dietary compliance among those with dyslipidemia within this high risk group of patients with recent AMI.

Almost $90 \%$ of patients enrolled in TRIUMPH had documented dietary counseling at hospital discharge, yet we found no relationship between the provision of dietary counseling and fast food intake 6 months after AMI. This may reflect variations in the intensity and quality of dietary education provided during the index hospitalization, which has been observed with counseling for smoking cessation after AMI. Prior studies have reported that mere documentation of smoking cessation counseling was not associated with improved smoking cessation after AMI. ${ }^{18,19}$ Thus, prior to considering the use of dietary counseling as a potential performance measure, it will be important to both demonstrate such counseling is associated with improved outcomes as well as to identify which components of dietary counseling are linked to improved care and outcomes.

Our data should be interpreted in the context of several potential limitations. First, our assessment of fast food intake was obtained by self-report, which could have resulted in misclassification. However, a similar single-item question assessing fast food intake has been shown to be associated with poor diet quality in the Multi-Ethnic Study of Atherosclerosis cohort. ${ }^{3}$ Moreover, any misclassification would be expected to be nondifferential and would have biased our results toward the null; therefore, any misclassification should have underestimated the strength of associations between patient characteristics and frequent fast food intake. Additionally, we did not ask patients what items they ate at fast food restaurants, and some fast food restaurants offer healthy dietary options. However, greater fast food consumption in our study was association with less favorable red blood cell omega-3 fatty acid levels, consistent with selection of less healthy options at fast food restaurants. Another limitation of our findings is the proportion of patients who were unable to complete the 6-month interview process. However, weighting our model with the reciprocal of the propensity to be missing 6-month follow-up resulted in no differences in our results. This suggests that these missing data did not introduce significant bias into our results. It is also worth noting that TRIUMPH hospitals were predominantly located in urban centers and did not include rural hospitals and hospitals from the West coast. There may be regional differences in fast food consumption throughout the US and our results may not be generalizable to those regions. Finally, this study was an observational investigation and no causal inferences can be drawn from these findings. However, our report provides important initial insights into the patterns and correlates of fast food intake in AMI patients.

\section{Acknowledgments}

Funding Support:

The TRIUMPH study was funded by a grant from the NHLBI (P50 HL 077113). Drs. Salisbury and Spertus are funded, in part, by an award from the American Heart Association Pharmaceutical Round Table and David and Stevie Spina. 


\section{References}

1. Mehta RH, Montoye CK, Faul J, Nagle DJ, Kure J, Raj E, Fattal P, Sharrif S, Amlani M, Changezi HU, Skorcz S, Bailey N, Bourque T, LaTarte M, McLean D, Savoy S, Werner P, Baker PL, DeFranco A, Eagle KA. Enhancing quality of care for acute myocardial infarction: shifting the focus of improvement from key indicators to process of care and tool use: the American College of Cardiology Acute Myocardial Infarction Guidelines Applied in Practice Project in Michigan: Flint and Saginaw Expansion. J Am Coll Cardiol. 2004; 43:2166-2173. [PubMed: 15193675]

2. Bonow RO, Bennett S, Casey DE Jr, Ganiats TG, Hlatky MA, Konstam MA, Lambrew CT, Normand SL, Pina IL, Radford MJ, Smith AL, Stevenson LW, Burke G, Eagle KA, Krumholz HM, Linderbaum J, Masoudi FA, Ritchie JL, Rumsfeld JS, Spertus JA. ACC/AHA Clinical Performance Measures for Adults with Chronic Heart Failure: a report of the American College of Cardiology/ American Heart Association Task Force on Performance Measures (Writing Committee to Develop Heart Failure Clinical Performance Measures): endorsed by the Heart Failure Society of America. Circulation. 2005; 112:1853-1887. [PubMed: 16160201]

3. Moore LV, Diez Roux AV, Nettleton JA, Jacobs DR, Franco M. Fast-food consumption, diet quality, and neighborhood exposure to fast food: the multi-ethnic study of atherosclerosis. Am J Epidemiol. 2009; 170:29-36. [PubMed: 19429879]

4. Harris WS, Von Schacky C. The Omega-3 Index: a new risk factor for death from coronary heart disease? Prev Med. 2004; 39:212-220. [PubMed: 15208005]

5. Harris WS. The omega-3 index as a risk factor for coronary heart disease. Am J Clin Nutr. 2008; 87:1997S-2002S. [PubMed: 18541601]

6. Spitzer RL, Kroenke K, Williams JB. Validation and utility of a self-report version of PRIME-MD: the PHQ primary care study. Primary Care Evaluation of Mental Disorders. Patient Health Questionnaire. JAMA. 1999; 282:1737-1744. [PubMed: 10568646]

7. Kroenke K, Spitzer RL, Williams JB. The PHQ-9: validity of a brief depression severity measure. J Gen Intern Med. 2001; 16:606-613. [PubMed: 11556941]

8. Gilbody S, Richards D, Brealey S, Hewitt C. Screening for depression in medical settings with the Patient Health Questionnaire (PHQ): a diagnostic meta-analysis. J Gen Intern Med. 2007; 22:15961602. [PubMed: 17874169]

9. Raghunathan, TESP.; Van Hoewyk, J. IVEware: Imputation and Variance Estimation Software User Guide. Ann Arbor, Michigan: Survey Research Center, Institute for Social Research University of Michigan; 2002.

10. Antman EM, Anbe DT, Armstrong PW, Bates ER, Green LA, Hand M, Hochman JS, Krumholz HM, Kushner FG, Lamas GA, Mullany CJ, Ornato JP, Pearle DL, Sloan MA, Smith SC Jr, Alpert JS, Anderson JL, Faxon DP, Fuster V, Gibbons RJ, Gregoratos G, Halperin JL, Hiratzka LF, Hunt SA, Jacobs AK. ACC/AHA guidelines for the management of patients with ST-elevation myocardial infarction: a report of the American College of Cardiology/American Heart Association Task Force on Practice Guidelines (Committee to Revise the 1999 Guidelines for the Management of Patients with Acute Myocardial Infarction). Circulation. 2004; 110:e82-e292. [PubMed: 15339869]

11. Anderson JL, Adams CD, Antman EM, Bridges CR, Califf RM, Casey DE Jr, Chavey WE 2nd, Fesmire FM, Hochman JS, Levin TN, Lincoff AM, Peterson ED, Theroux P, Wenger NK, Wright RS, Smith SC Jr, Jacobs AK, Halperin JL, Hunt SA, Krumholz HM, Kushner FG, Lytle BW, Nishimura R, Ornato JP, Page RL, Riegel B. ACC/AHA 2007 guidelines for the management of patients with unstable angina/non ST-elevation myocardial infarction: a report of the American College of Cardiology/American Heart Association Task Force on Practice Guidelines (Writing Committee to Revise the 2002 Guidelines for the Management of Patients With Unstable Angina/ Non ST-Elevation Myocardial Infarction): developed in collaboration with the American College of Emergency Physicians, the Society for Cardiovascular Angiography and Interventions, and the Society of Thoracic Surgeons: endorsed by the American Association of Cardiovascular and Pulmonary Rehabilitation and the Society for Academic Emergency Medicine. Circulation. 2007; 116:e148-e304. [PubMed: 17679616] 
12. Dynesen AW, Haraldsdottir J, Holm L, Astrup A. Sociodemographic differences in dietary habits described by food frequency questions--results from Denmark. Eur J Clinc Nutr. 2003; 57:15861597.

13. Kant AK, Graubard BI. Secular trends in the association of socio-economic position with selfreported dietary attributes and biomarkers in the US population: National Health and Nutrition Examination Survey (NHANES) 1971-1975 to NHANES 1999-2002. Public Health Nutr. 2007; 10:158-167. [PubMed: 17261225]

14. Mullie P, Clarys P, Hulens M, Vansant G. Dietary patterns and socioeconomic position. Eur J Clin Nutr. 2010; 64:231-238. [PubMed: 20087378]

15. Johansson L, Thelle DS, Solvoll K, Bjorneboe GE, Drevon CA. Healthy dietary habits in relation to social determinants and lifestyle factors. Br J Nutr. 1999; 81:211-220. [PubMed: 10434847]

16. Stewart H, Blisard N, Jolliffe D. Do Income Constraints Limit Spending on Fruits and Vegetables Among Low-Income Households? Journal of Agricultural and Resource Economics. 2003; 28:465-480.

17. Lin, B-H.; Frazao, E.; Guthrie, JF. Away-From-Home Foods Increasingly Important to Quality of American Diet. US Department of Agriculture ERS; Washington, D.C.: 1999.

18. Dawood N, Vaccarino V, Reid KJ, Spertus JA, Hamid N, Parashar S. Predictors of smoking cessation after a myocardial infarction: the role of institutional smoking cessation programs in improving success. Arch Intern Med. 2008; 168:1961-1967. [PubMed: 18852396]

19. Reeves GR, Wang TY, Reid KJ, Alexander KP, Decker C, Ahmad H, Spertus JA, Peterson ED. Dissociation between hospital performance of the smoking cessation counseling quality metric and cessation outcomes after myocardial infarction. Arch Intern Med. 2008; 168:2111-2117.

[PubMed: 18955640] 


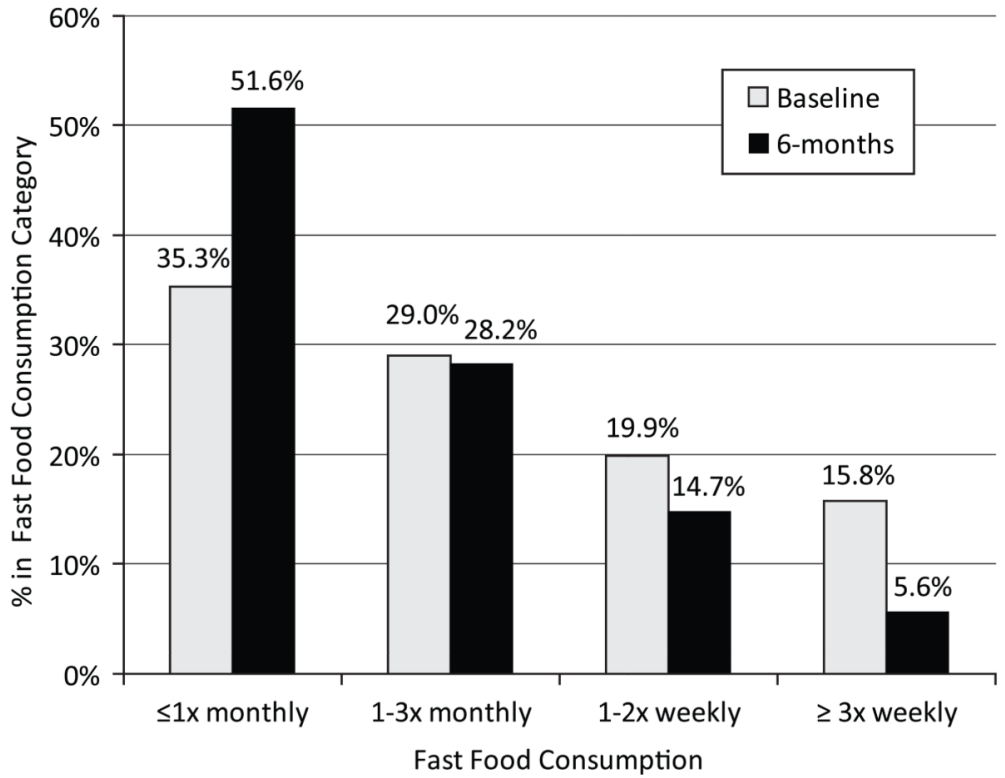

Figure 1. Fast Food Consumption at the Time of Acute Myocardial Infarction and at 6 Month Follow-up

Frequency of patient-reported fast food consumption at the time of AMI and at the 6 month follow-up assessment. 


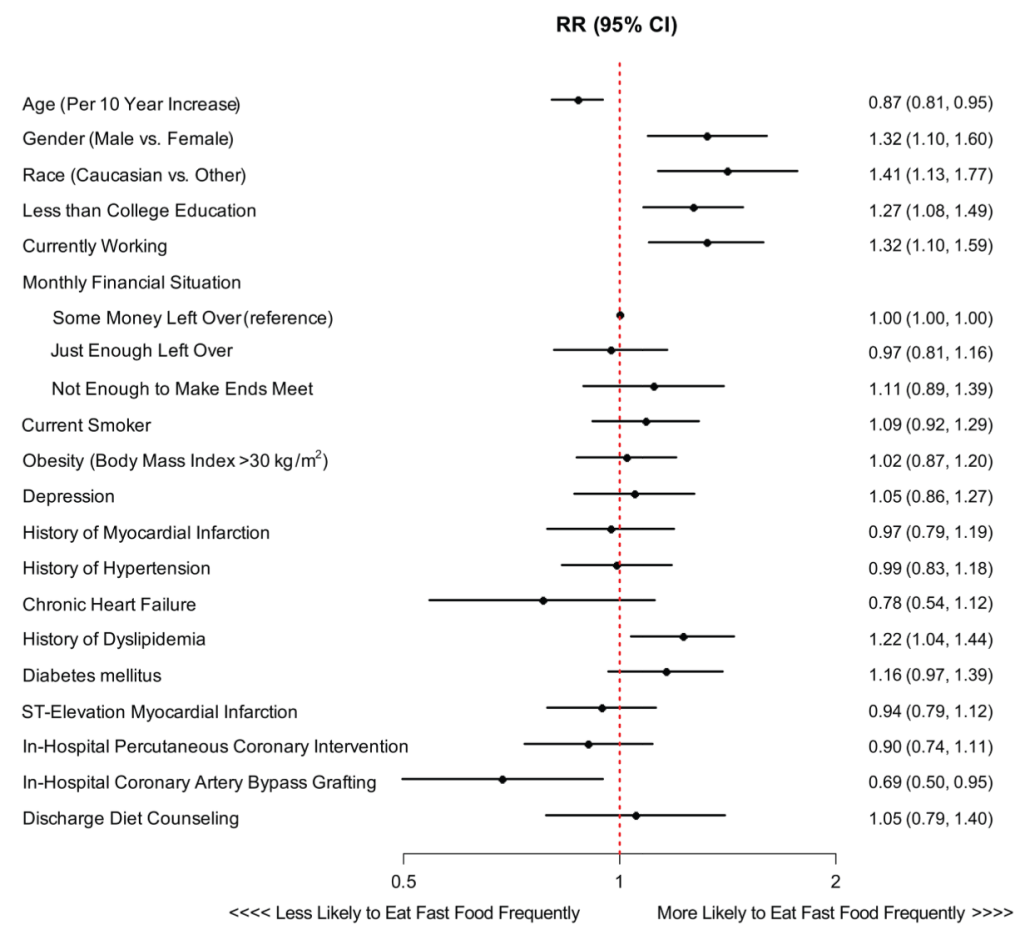

Figure 2. Predictors of Weekly Fast Food Consumption 6 Months After Acute Myocardial Infarction

Patient characteristics associated with frequent fast food intake at 6 month follow-up assessment after acute myocardial infarction (relative risk, 95\% confidence interval). 
Table 1

Baseline Patient Characteristics of Patients With and Without Frequent Fast Food Intake 6 months After Acute Myocardial Infarction

\begin{tabular}{|c|c|c|c|}
\hline Variable & Frequent Fast Food $(\mathrm{n}=\mathbf{5 0 3})$ & Infrequent Fast Food $(n=1978)$ & P-value \\
\hline Age & $57.3 \pm 11.4$ & $60.5 \pm 11.8$ & $<0.001$ \\
\hline Male & $380(75.5 \%)$ & $1308(66.1 \%)$ & $<0.001$ \\
\hline Caucasian & $384(76.3 \%)$ & $1442(73.1 \%)$ & 0.143 \\
\hline Education (Less than college) & $265(52.7 \%)$ & $916(46.4 \%)$ & 0.012 \\
\hline Health Insurance Payer & & & 0.270 \\
\hline Preferred Provider Organization & $230(46.2 \%)$ & $851(43.8 \%)$ & \\
\hline Health Maintenance Organization & $56(11.2 \%)$ & $248(12.8 \%)$ & \\
\hline Medicare/Medicaid/Veterens Affairs & $105(21.1 \%)$ & $473(24.3 \%)$ & \\
\hline Self & $90(18.1 \%)$ & $297(15.3 \%)$ & \\
\hline Other & $17(3.4 \%)$ & $75(3.9 \%)$ & \\
\hline Avoids Care Due to Cost & $118(23.7 \%)$ & $446(22.8 \%)$ & 0.652 \\
\hline Monthly Finances & & & 0.266 \\
\hline Some money left over & $224(45.3 \%)$ & $914(46.9 \%)$ & \\
\hline Just enough to make ends meet & $172(34.7 \%)$ & $705(36.2 \%)$ & \\
\hline Not enough to make ends meet & $99(20.0 \%)$ & $329(16.9 \%)$ & \\
\hline Married & $285(56.8 \%)$ & $1134(57.4 \%)$ & 0.794 \\
\hline Work Full or Part Time & $290(58.0 \%)$ & $927(47.2 \%)$ & $<0.001$ \\
\hline Body mass index $\left(>30 \mathrm{~kg} / \mathrm{m}^{2}\right)$ & $204(42.3 \%)$ & $772(40.7 \%)$ & 0.511 \\
\hline Diabetes mellitus & $150(29.8 \%)$ & $550(27.8 \%)$ & 0.370 \\
\hline History of hypertension & $316(62.8 \%)$ & $1300(65.7 \%)$ & 0.223 \\
\hline History of dyslipidemia & $262(52.1 \%)$ & $992(50.2 \%)$ & 0.438 \\
\hline Chronic Kidney Disease & $32(6.4 \%)$ & $113(5.7 \%)$ & 0.580 \\
\hline Current Smoker & $210(42.1 \%)$ & $690(35.0 \%)$ & 0.004 \\
\hline Chronic Heart Failure & $29(5.8 \%)$ & $142(7.2 \%)$ & 0.264 \\
\hline Depression (Patient Health Questionnaire-9 $\geq 10$ ) & $96(20.0 \%)$ & $321(17.2 \%)$ & 0.154 \\
\hline Peripheral Vascular Disease & $24(4.8 \%)$ & $100(5.1 \%)$ & 0.794 \\
\hline Prior Stroke & $20(4.0 \%)$ & $92(4.7 \%)$ & 0.515 \\
\hline History of Prior Myocardial Infarction & $102(20.3 \%)$ & $401(20.3 \%)$ & 0.998 \\
\hline
\end{tabular}




\begin{tabular}{|c|c|c|c|}
\hline Variable & Frequent Fast Food $(n=503)$ & Infrequent Fast Food $(n=1978)$ & P-value \\
\hline History of Prior Coronary Artery Bypass Grafting & $61(12.1 \%)$ & $236(11.9 \%)$ & 0.904 \\
\hline Final Myocardial Infarction Diagnosis & & & 0.985 \\
\hline ST-elevation Myocardial Infarction & $223(44.3 \%)$ & $876(44.3 \%)$ & \\
\hline Non-ST segment Elevation Myocardial Infarction & $280(55.7 \%)$ & $1102(55.7 \%)$ & \\
\hline In-Hospital Revascularization & & & 0.096 \\
\hline None & $134(26.6 \%)$ & $482(24.4 \%)$ & \\
\hline Percutaneous Coronary Intervention & $330(65.6 \%)$ & $1281(64.8 \%)$ & \\
\hline Coronary Artery Bypass Grafting & $39(7.8 \%)$ & $215(10.9 \%)$ & \\
\hline Number of coronary arteries diseased & $1.7 \pm 0.9$ & $1.6 \pm 0.9$ & 0.526 \\
\hline Total Cholesterol (mg/dl) & $156.8 \pm 36.3$ & $156.1 \pm 38.0$ & 0.767 \\
\hline High Density Lipoprotein (mg/dl) & $38.8 \pm 10.4$ & $41.6 \pm 13.0$ & $<0.001$ \\
\hline Low Density Lipoprotein (mg/dl) & $99.7 \pm 35.0$ & $97.9 \pm 35.4$ & 0.307 \\
\hline Triglycerides (mg/dl) & $167.4 \pm 136.3$ & $145.3 \pm 100.5$ & $<0.001$ \\
\hline Hemoglobin A1c (\%) & $6.5 \pm 1.7$ & $6.6 \pm 2.0$ & 0.872 \\
\hline Glucose (mg/dl) & $160.2 \pm 85.5$ & $157.7 \pm 83.1$ & 0.548 \\
\hline Discharge Diet Counseling & $461(91.7 \%)$ & $1795(90.7 \%)$ & 0.529 \\
\hline Referral for Outpatient Cardiac Rehabilitation & $208(41.4 \%)$ & $755(38.2 \%)$ & 0.191 \\
\hline
\end{tabular}

